\title{
ДОПОЛНИТЕЛЬНОЕ ПРОФЕССИОНАЛЬНОЕ ОБРАЗОВАНИЕ В ВУЗЕ КУЛЬТУРЫ
}

\section{ADDITIONAL VOCATIONAL EDUCATION AT THE UNIVERSITY OF CULTURE \\ E. Mulyavina \\ I. Omelchenko}

Summary: The aim of the survey is to study the problem of implementing additional professional programs at the university of culture. The authors consider additional professional education as a form of adult education, which allows you to adjust a person's professional choice, to form the necessary set of competencies that meet the requirements of professional standards and the needs of the employer.

Keywords: additional professional education, professional retraining, employer, national projects, competencies.

\author{
Мулявина Элеонора Александровна, \\ К.n.н., доцент, Тюменский государственный институт \\ культуры \\ emulyavina@rambler.ru \\ Омельченко Игорь Николаевич, \\ К.п.н., и.о. ректора, Тюменский государственный \\ институт культуры \\ omelsemerka@mail.ru
}

Аннотация: Целью исследования является изучение проблемы реализации дополнительных профессиональных программ в вузе культуры. В качестве методов решения рассматриваемой проблемы выступает анализ востребованности дополнительного профессионального образования как формы образования взрослых, позволяющей скорректировать профессиональный выбор человека, сформировать необходимый набор компетенций, соответствующий требованиям профессиональных стандартов и запросам работодателя.

Ключевые слова: дополнительное профессиональное образование, профессиональная переподготовка, работодатель, национальные проекты, компетенции.

фессиональное образование - это именно то направление, которое сейчас выступает инструментом решения кадровых проблем. В подтверждение этих слов можно процитировать Указ президента Российской Федерации от 07.05.2018 № 204 «О национальных целях и стратегических задачах развития РФ на период до 2024 года». В документе, наряду с другими, поставлены следующие задачи в области образования:

- модернизация профессионального образования, в том числе посредством внедрения адаптивных, практико-ориентированных и гибких образовательных программ;

- формирование системы непрерывного обновления работающими гражданами своих профессиональных знаний и приобретения ими новых профессиональных навыков...» [2].

О значимости дополнительного профессионального образования, на наш взгляд, говорит и тот факт, что с 1 января 2019 года учреждения ДПО обязаны вносить сведения о выданных слушателям документах в Федеральный реестр сведений документов об образовании и (или) квалификации, документов об обучении (так называемая ФИС ФРДО). Благодаря этому работодатель сможет проверить уровень квалификации работника, а работник - убедиться, что полученный диплом является подлинным.

Вступившие в действие с 01.01.2019 Национальные 
проекты «Образование», «Культура», «Демография» также отводят дополнительному профессиональному образованию важную роль. Согласно плану реализации этих проектов, число обученных по программам непрерывного образования в образовательных организациях высшего образования, реализующих дополнительные образовательные программы и программы профессионального обучения, возрастет с 1,9 млн человек в 2019 году до 3 млн к 2024 году. Число специалистов, занятых в сфере культуры, повысивших свою квалификацию возрастет с 14 тыс. человек в 2019 г до 200 тыс. человек в 2024 году. Без сомнения, для этого потребуются немалые усилия сотрудников системы ДПО в сфере образования и культуры. А создание интеграционной платформы непрерывного образования облегчит потребителям поиск нужных образовательных программ и образовательных учреждений, их предлагающих.

Таким образом, очевидно, что дополнительное профессиональное образование представляет весьма значимое направление в структуре современного отечественного образования. Центр дополнительного профессионального образования Тюменского государственного института культуры стремится следовать современным тенденциям.

Ежегодно институтом реализуется более 40 программ дополнительного профессионального образования. Их тематика представлена следующими укрупненными направлениями:

- социально-культурный сервис. Коммуникации. Досуговая деятельность;

- музыка, театр, хореография. Методика преподавания;

- визуальные искусства. Методика преподавания;

- музеи. Живопись. Декоративно-прикладное искусство;

- библиотечно-информационная деятельность;

- культурология. Педагогика и психология;

- туризм, гостиничный бизнес;

- экскурсионная деятельность.

В их реализации задействованы как штатные сотрудники института, так и приглашенные специалисты. Это руководители, заместители руководителей, ведущие профессионалы сферы культуры.

Анализируя контингент слушателей, можно с уверенностью сказать о том, что происходит неуклонный рост числа желающих, обучаться на программах профессиональной переподготовки. Работодатели стали более требовательными к соискателям, следуют по пути максимальной оптимизации человеческих ресурсов. Есть специальности, где без наличия второго диплома о профессиональной переподготовке, перспектив карьерного роста и личностного развития просто нет. Введение в действие с 2020 года профессиональных стандартов, в том числе в сфере культуры, заставляет работодателей пересматривать отношения с сотрудниками, не имеющими специального образования. И это тоже одна из причин повышения спроса на дополнительное профессиональное образование. Мы считаем, что наши программы профессиональной переподготовки сейчас выступают в качестве «моста» между бакалавриатом, как ступенью образования, и теми требованиями, которые работодатель предъявляет к конкретной штатной единице, расширяя перечень имеющихся у работника компетенций [3].

Перечень программ профессиональной переподготовки, реализуемый в настоящее время в институте включает в себя ряд направлений. Одно из них - «Библиотечно-информационная деятельность». Здесь предлагаются несколько профилей: «Информационно-аналитическая деятельность»; «Технолог автоматизированных библиотечно-информационных систем»; «Менеджер информационных ресурсов»; «Библиотечно-информационное обеспечение потребителей информации»; «Педагог-библиотекарь». Наиболее востребованы профили, занимающие две крайние позиции.

Популярно и направление «Социально-культурная деятельность». Предлагаемые профили: «Управление учреждениями культуры», «Арт-менеджмент», «Постановка и продюссирование культурно-досуговых программ», «Менеджмент социально-культурной сферы».

Неизменный спрос имеют программы: «Режиссура театрализованных представлений и праздников»; «Декоративно-прикладное искусство и народные промыслы: художественный текстиль; художественная керамика», «Хореографическое искусство»; «Искусство народного пения»; «Живопись» и другие. Потребность в таких образовательных программах растет с каждым годом [4].

Учитывая пожелания заказчиков, предложения кафедр института, а также актуальные тенденции в дополнительном образовании, Центр ДПО разрабатывает план на календарный год и предлагает его потенциальным заказчикам.

Bсе эти программы ориентированы на внешнего потребителя, людей, которые закончили обучение по государственным образовательным стандартам третьего, второго поколения и даже раньше. Но те, кто сейчас являются студентами, также задумываются о расширении своих возможностей на рынке труда. И пока футурологи от педагогики решают, как подготовить подрастающее поколение к жизни в ближайшие десятилетия, чему их учить, какие профессии им следует предлагать к освоению, мы уже сейчас даем возможность нашим выпускникам расширять свою конкурентоспособность 
на рынке труда по горизонтали. За счет параллельного освоения основных и дополнительных образовательных программ, разработанных кафедрами образовательных модулей по профилям, дающим дополнительные к основной образовательной программе компетенции. Закончив обучение по основной образовательной программе и параллельно освоив дополнительную образовательную программу, студент сможет получить вместе с дипломом бакалавра и диплом о дополнительном профессиональном образовании установленного образца, дающий право на ведение профессиональной деятельности в соответствующей сфере.

Таким образом, дополнительное профессиональное образование сейчас - это своего рода инструмент приведения в соответствие образовательного статуса, компетенций, приобретенных людьми в прежние годы и имеющихся у сотрудников на сегодняшний день, с требованиями времени и рынка труда.

\section{ЛИТЕРАТУРА}

1. Федеральный закон «0б образовании в Российской Федерации» от 29.12.2012 № 273-Ф3

2. Указ Президента Российской Федерации от 07.05.2018 № 204 «0 национальных целях и стратегических задачах развития РФ на период до 2024 года» (В редакции Указа Президента Российской Федерации от 19.07. 2018 г. № 444).

3. Мулявина, Э.А., Дополнительное профессиональное образование как инструмент удовлетворения образовательных потребностей населения / Э.А. Мулявина // Актуальные проблемы художественного образования: сборник докладов Всероссийской научно-практической конференции «Дополнительное профессиональное образование в сфере культуры и искусства: опыт, проблемы». - Томск, 2014. - с. 185 - 189.

4. Мулявина, Э.А. Проектирование содержания дополнительного профессионального образования на основе профессиональных стандартов Э.А. Мулявина // Практико-ориентированная подготовка педагогов-исследователей в системе профессионального образования: сборник статей по материалам Всероссийской научно-практической конференции / Тюмень: Тюменский государственный университет, 2016. - С. 216 - 222.

( ) Мулявина Элеонора Александровна (emulyavina@rambler.ru), Омельченко Игорь Николаевич (omelsemerka@mail.ru).

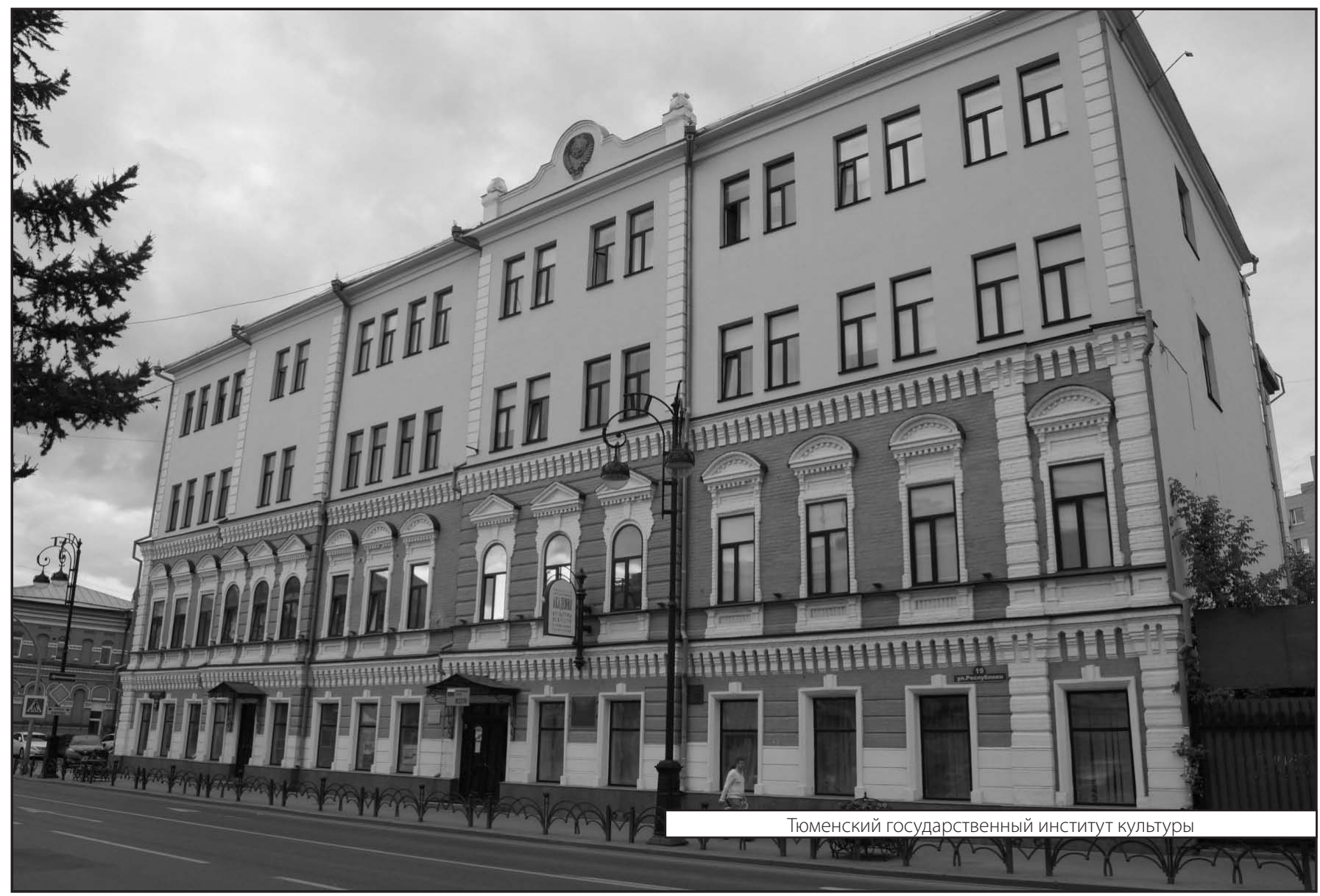

